kidneys; whereas glucose can be destroyed in certain proportions.

3. Cane-sugar would be beneficial to a certain extent; as when taken into the intestine it is in part at least transformed into glucose; but if given in too large proportions to be thus completely transformed, the disease would be probably aggrarated by the presence in the blood, and subsequent excretion by the kidneys, of the former variety of sugar.

4. The glucose should be given in moderate quantities at a time, and frequently, ratber than in large quantities at long intervals; because, when much sugar is taken fasting, it is absorbed too quickly to admit of its complete destruction in the liver, and it passes into the general circulation, whence it is eliminated in the urine.

\section{TOPOGRAPHY AND CLIMATE OF LLANDUDNO, NORTH WALES.}

By T. C. RODEN, F.R.C.S.

LIANDUDNo, as the guide-books inform us, stands on an arm of land about four miles in length, jutting out towards the west from the mainland of North Wales at Conway. This little peninsula is terminated by a huge limestone rock, seven miles in circumference, and 750 feet in height-the Great Orme's Head-under and along the south side of which the town is built. About a couple of miles in front-that is, to the south-runs a chain of hills from the Little Orme's Head on the east towards Conway bay on the west; while a beautiful semicircular sweep of the ground between the two Ormes encloses the wators of Llandudno bay. It is chiefly this peculiar formation of the locality which impresses it with distinctive qualities, beneficial to particular classes of invalids; while the general mildness, dryness, and salubrity of the air render it an agreeable place of resort to all. From the experience of a residence of three years, I am enabled to designate the climate as mild, yet bracing, and remarkably free from humidity.

It is generally supposed by strangers that the coast of North Wales is cold and bleak; and many who visit this spot find it difficult to account for the opposite state of the case with regard to Llandudno. The shelter afforded by the Great Orme's Head from the north and north-east winds, together with the peninsular form of the site, afford the true explanation of the fact; for, being embraced on three sides by the sea, the temperature becomes more equalised. In winter, the water being warmer than the air, imparts a portion of its caloric to the atmosphere; while in summer the phenomena are reversed. The Gulf Stream, too, passing the south coast of Ireland, probably produces no unimportant share in the result.

These circumstances will make intelligible the quality of mildness, which is most striking in the winter months; so much so is this the case, that there are few points on the British coast so well fitted for the abode of invalids in winter as this. The thermometer fully bears out this statement; for my observations of it, noted regularly during two years, prove that the temperature is milder by $10^{\circ}$ or $15^{\circ}$ in severe weather, than in several situations in England with which I have compared it; and the contrast is the greater the more intense the cold.

It might naturally be expected, therefore, that in summer the heat would be more oppressive here than elsewhere. That it is not so, one or two facts will serve to show. The range of hills to the sonth, before alluded to, and the monntain on the north, bound a valley, along which the westerly winds (which generally prevail), cooled by the sea over which they sweep, pass in a grateful and refreshing current, and produce, together with the refrigerating influence of the volumes of water around, a temperature certainly not higher than that of other places, and lower than many. To substantiate this, I need only mention that from observations taken at the telegraph station on the mountain (at an altitude seven hundred feet above the level of the sea) during the hot weather of last summer, it appeared that the thermometer was usually about $5^{\circ}$ higher than in the town below.

From what has already been said, it will excite no surprise that within the space of a square mile Llandudno should possess two or three varieties of climate. That part of the valley exposed more directly to the action of the winds is cooler in the summer, and in the winter is so bracing as to lead few to prefer it; at the foot of the Great Orme the temperature is mild at all seasons; while on the mountain side that delicious atmosphere emphatically called " mountain air" gives life and strength to the system. The variations are not so trivial as might be imagined, but are well marked, and are severally adapted to the constitutions and requirements of different individuals. Invalids may therefore select a residence suited to their respective cases during any and every part of the year-either completely sheltered, or more or less open to bracing influences.

It is, however, to the advantages of the place as a winter residence, as not being generally understood, that I would particularly direct attention. The beauties of the scenery, the extraordinary opportunities for sea-bathing at all states of the tide, the purity and salubrity of the air, the facility of reaching all points of interest in North Wales, as well as of access to England, are already well known; but comparatively few have enabled themselves to judge of the climate from a sufficiently long residence. Visitors generally have been content to enjoy the pleasures of the scene for a time in the summer, and have probably felt a sort of compassion for those destined to spend the cold season, as they imagine, on these inclement and in hospitable shores. Far different, however, is the case of those who commit themselves to a Llandudno winter. The charms of its bright and sunny skies, clear and exhilarating air, and genial temperature-the advantages of its freedom from damp, fog, and continuous rain, and from the intense cold of most situations in northern latitudes, render it for the most part unnecessary to expatriate the weakly in health and constitution, or to seek abroad for conditions which may be ensured at home.

For the victims of dyspepsia, of rheumatism even in its severest instances, of phthisis and the various forms of pulmonary and bronchial disease, as well as for that large class of persons technically termed "delicate", the winter climate of Llandudno is admirably adapted. Several such who have, within the last few years, taken up their abode here, have experienced great benefit, and have in a remarkable degree recovered their health. Scarcely for a day throughout the year need the valetudinarian keep within doors, or refrain from that exercise in the open air so essential for the maintenance or restoration of health.

I submit, then, that these facts incontestably prove that this new watering-place is a valuable addition to the hygienic resources of the profession, as supplying a desideratum long sought for, too often perhaps on foreign shores, and certainly not hitherto realised at home.

Some meteorological and local details are reserved for a future communication.

\section{POISONING BY ALMOND FLAVOUR : RECOVERY}

By Henry W. T. Euris, Esq., Crowle, Bawtry.

AT four o'clock in the afternoon of last Friday, I was summoned to visit immediately the wife of Mr. Frederick Chapman, a solicitor's clerk, of this place, who was said to be in a fit. On proceeding to the house, I found my patient lying on her back across the bed, in a complete state of insensibility; her countenance was ghastly; her eyes were fixed, staring, and prominent; the pupils were dilated; the jaws firmly closed; frothy mucus exuded from the mouth; the breathing was heavy and stertorous; the pulse at the wrist was scarcely perceptible, but the carotids pulsated strongly; the extremities were relaxed. Whilst noticing these symptoms, I detected the odour of hydrocyanic acid; and, on inquiry, ascertained there had been some slight vomiting of undigested meat. This at once and unmistakeably revealed the nature of the case. Of course, not a moment was to be lost; cold affusion was therefore instantly and vigorously had recourse to, followed up by ammonia to the nostrils, and its application with camphor liniment to the chest, and with mustard to the legs. These means were persisted in for about two hours, with but slight change in the symptoms. At the end of that time, howerer, there were convulsive twitchings, rolling of the eyeballs, etc. In another hour, the patient became delirious, tossing herself wildly about, but gradually subsiding into sleep. Twenty leeches were in the meantime applied to the head, and warmth to the extremities (previously quite cold). Emetics and the stomachpump were at hand, but could not be used : in fact, from the time that had elapsed before I saw her (ten to fifteen minutes after swallowing the poison), it is doubtful whether they could have been of any avail, absorption taking place so rapidly.

The case has since gone on well, the only drawback being erysipelas of the face and scalp, attributable, probably, to the leech-bites. 